\title{
Electrochemical Oxidation Effect of Each Ascorbic Acid and Folic Acid on Lead Ions in Human Blood
}

\author{
Muhammed Mizher Radhi, ${ }^{1,}$, Sura Ali Al-Assady ${ }^{1}$, Nadia Tareq Barakat ${ }^{2}$, \\ Ammani Jassim Mohammed ${ }^{3}$, Ibtihal Hashim Aziz ${ }^{3}$ \\ ${ }^{1}$ Health and Medical Technology College, Radiological Techniques Department, Middle Technical University, Baghdad, Iraq \\ ${ }^{2}$ Iraqi Center for Cancer and Medical Genetic Research, Almustensyria University, Baghdad, Iraq \\ ${ }^{3}$ Health and Medical Technology College, Analytical Lab. Techniques Department, Middle Technical University, Baghdad, Iraq
}

Email address:

mmradhi@yahoo.com (M. M. Radhi)

${ }^{*}$ Corresponding author

\section{To cite this article:}

Muhammed Mizher Radhi, Sura Ali Al-Assady, Nadia Tareq Barakat, Ammani Jassim Mohammed, Ibtihal Hashim Aziz. Electrochemical Oxidation Effect of Each Ascorbic Acid and Folic Acid on Lead Ions in Human Blood. International Journal of Pharmacy and Chemistry. Vol. 3, No. 3, 2017, pp. 33-40. doi: 10.11648/j.ijpc.20170303.12

Received: September 21, 2016; Accepted: November 26, 2016; Published: May 6, 2017

\begin{abstract}
Electrochemical studies by cyclic voltammetric (CV) method provide high potential for investigation of oxidant pollutant compounds such as $\mathrm{Pb}(\mathrm{II})$. Glassy carbon electrode (GCE) can be used for the potentiostatic analysis of the lead ions in different electrolyte especially human blood medium to studying the effect of the lead ions on the blood components. The results of this study were found that oxidation and reduction current peaks of lead ions in $1 \mathrm{M} \mathrm{KCl}$ is high value and enhanced by adding ascorbic acid (AA) solution, while in human blood medium was disappearing the reduction current peak and enhance the oxidation current peak by lead ions. It means that lead ions in blood medium act as an oxidative reagent and causes problem in the decomposition of the blood component. Also, it was found that using folic acid (FA) solution with lead ions in blood medium causes the enhancement of reduction current peaks of lead ion and decreasing for oxidation current peaks, so this means that folic acid solution acts as antioxidative reagent in present of lead ions in blood medium, it may recommended to taking tablet of FA for the patients who suffers to lead pollution.
\end{abstract}

Keywords: $\mathrm{Pb}(\mathrm{II})$, Cyclic Voltammetry, Human Blood, Redox Process, FA, AA

\section{Introduction}

The pollution effect of lead ions was studied in human blood at different researches [1-6]. In the new present studies were used electrochemistry techniques to found the oxidative effect of pollutants such as some heavy metals in blood samples [7-10].

Electrochemical methods provide for investigation of antioxidant compounds, assessment of antioxidant capacity, and measurement of electrochemical index. Different types of electrodes can be used for the assay purposes. The devices can be stationary or flow through, and based on cyclic or differential pulse voltammetry as well as potentiostatic analysis. The methods are known for their suitability for food control and monitoring the levels of antioxidant capacity in other biological samples and matrices [11].

A number of laboratory methods are available to determine blood lead concentrations. The most common are atomic absorption spectrometry (AAS), anodic stripping voltammetry (ASV) and inductively coupled plasma mass spectrometry (ICP-MS). In addition, a simple to use, portable device using ASV technology is available for performing blood lead measurements at point of care. These methods differ significantly in their analytical capacities (e.g. limits of detection, accuracy), costs (e.g. purchase and maintenance costs, laboratory infrastructure required, reagents and supplies) and technical requirements (e.g. sample preparation, calibration, skilled personnel). These factors, taken in conjunction with the setting and resources of the laboratory, will influence the decision about the choice of method [12].

The transfer of $\mathrm{Pb}(\mathrm{II})$ assisted by 8 -hydroxyquinoline (8-QH) present in the methyl isobutyl ketone (MIBK) across the water/MIBK interface was systematically investigated by novel 
electrolyte dropping electrode (EDE) using cyclic voltammetry (CV) and square wave voltammetry (SWV). The transfer peak current was proportional to the concentration of $\mathrm{Pb}(\mathrm{II})$ within the broad range from $5 \times 10^{-7} \mathrm{~mol} / \mathrm{L}$ to $2 \times 10^{-5} \mathrm{~mol} / \mathrm{L}$. The presented procedure demonstrated that this novel method has good sensitivity and stability in the quantitative detection of heavy metal ions, and can be applied to online environmental monitoring [13].

Haemoglobin is the oxygen transporter within the red blood cell. The oxygenation reaction is accompanied by release or uptake of protons depending on the $\mathrm{pH}$. The electroactive nature of the reaction between haemoglobin and oxygen renders the binding study suitable for investigation by electrochemical method. The values of the peak current are sufficiently distinct to allow for rapid determination of these phenotypes. The method is simple and faster than the conventional electrophoretic method and removes the need to use standards once the characteristic values of peak current have been established. The good correlation between peak current and concentration also provides an accurate determination of the concentrations of haemoglobin samples [14].

Lead concentrations in blood samples typical of unexposed individuals are determined by using square-wave anodic stripping voltammetry at a disposable 287-element (15-35microns diameter) carbon microarray electrode. Analysis of a series of low $\mathrm{Pb}$-containing samples (blood $[\mathrm{Pb}]=17$ to 92 micrograms/L) by standard addition gives good accuracy (average bias vs graphite furnace atomic absorption spectroscopy $=-4$ micrograms $/ \mathrm{L}$ ) and precision (pooled $\mathrm{SD}=$ 7 micrograms/L). The signal/noise ratio is improved by about an order of magnitude over that found at a single carbon disk (10 microns diameter), resulting in a detection limit (for the microarray) of 5 micrograms/L for a 60 -s deposition of sample [15].

Lead as one part of heavy metals group pose a detrimental risk to human health and the environment due to its toxicity, even exposure to minuscule quantities can be life threatening. Levels of lead are not stable in the environment and vary according to industrial production, urbanization, climate changes and many other factors. It is not surprising that rapid, sensitive and simple analytical determination of metal ions in environment is very important. Electrochemical techniques are one of the best methods for detecting metals due to their low cost, high sensitivity and portability. Besides lead, cadmium was determined electrochemically and $\mathrm{Ca}$, $\mathrm{Mg}, \mathrm{Fe}, \mathrm{Zn}$ and $\mathrm{Cu}$ spectrometrically [16].

The anodic stripping peak current of lead on the glassy carbon electrode surface was greatly increased in the presence of high concentration of copper ion. The effects of supporting electrolyte, concentration of $\mathrm{Cu}^{2+}$, accumulation potential and accumulation time were studied on the stripping peak current of $\mathrm{Pb}^{2+}$. As a result, a sensitive, simple and rapid electrochemical method was developed for the detection of lead. It was used to detect the concentration of lead in blood samples, and the results consisted with the values that obtained by atomic absorption spectrometry [17].
A foam-like mesoporous polymer of melamineformaldehyde (mPMF) was synthesized and further deposited on disposable screen-printed electrodes (SPEs) for the electroanalysis of $\mathrm{Pb}^{2+}$ ions in blood. The mPMF-modified sensor could allow for the detection of $\mathrm{Pb}^{2+}$ ions in one drop of blood with a high detection selectivity, sensitivity (down to about $0.10 \mu \mathrm{g} \mathrm{L}^{-1} \mathrm{~Pb}^{2+}$ ions) and reproducibility. Such a simple "one-drop-of-blood" electroanalysis method equipped with disposable SPEs and a portable electrochemical transducer can be tailored for the field-deployable or on-site monitoring of blood $\mathrm{Pb}^{2+}$ levels in the clinical laboratory [18].

The fabrication and the performance of microfluidic paperbased electrochemical sensing devices (mPEDs) were comprised paper-based microfluidic channels patterned by photolithography or wax printing, and electrodes screenprinted from conducting inks (e.g., carbon or $\mathrm{Ag} / \mathrm{AgCl}$ ). The mPEDs are capable of quantifying the concentrations of various analytes (e.g., heavy-metal ions and glucose) in aqueous solutions. This low-cost analytical device should be useful for applications in public health, environmental monitoring, and the developing world [19].

As a result of industrialization lead is one of the most widely dispersed toxic heavy metals in the environment. There is a pressing need for a reliable, affordable and portable analytical technique for routine determination of lead at trace levels in biological and environmental samples. The detection limit for lead (II) was found low enough and the reproducibility is sufficient for routine determinations in biomedical samples (5 ppb, 6\%). The system can support a CDC recommended screening for blood lead levels and an on-site analysis of environmental samples as well. Under suitable conditions calibration free direct determinations can also be performed [20].

In this work, a new study in cyclic voltammetric technique using blood medium as an electrolyte to determination the effect of each of AA and FA on the redox current peaks of lead ions in blood medium.

\section{Experimental}

\subsection{Reagents and Chemicals}

Blood samples were used from healthy human in Baghdad hospital center. Lead chloride $\mathrm{PbCl}_{2}$ from Fluka (Germany), Ascorbic acid (AA) from Technicon chemicals Co. (Oreq. Tournai Belgique), $\mathrm{KCl}$ from SCRC (China), folic acid was used tablet from Actavis, Barnstaple, EX328NS, UK and other chemicals and solvents were of annular grade and used as received from the manufacturer. Double distilled water was used for the preparation of aqueous solutions. All solutions were deaerated with oxygen free nitrogen gas for 15 min prior to making the measurement. All experiments were done at room temperature $25^{\circ} \mathrm{C}$.

\subsection{Apparatus and Procedures}

Instruments: EZstat series (potentiostat/glvanostat) NuVant Systems Inc. pioneering electrochemical technologies USA. 
Electrochemical workstations of Bioanalytical system with potetiostate driven by electroanalytical measuring softwares was connected to personal computer to perform Cyclic Voltammetry $(\mathrm{CV})$, an $\mathrm{Ag} / \mathrm{AgCl}(3 \mathrm{M} \mathrm{NaCl})$ and Platinum wire (1 mm diameter) was used as a reference and counter electrode respectively. The glassy carbon working electrode (GCE) was used in this study and cleaning the surface by polishing Alumina (BASi compony USA).

\section{Results and Discussion}

\subsection{Identification of Redox Current Peaks of Pb(II) in Aqueous Solution}

Cyclic voltammetric technique was studied for lead ions in $1 \mathrm{M} \mathrm{KCl}$ as an electrolyte to identification of redox current peaks of $\mathrm{Pb}(\mathrm{II})$ using GCE in $\mathrm{CV}$ cell. Figure 1 shows there are two peaks of oxidation and reduction current peaks at $550 \mathrm{mV}$ and $-980 \mathrm{mV}$ respectively.

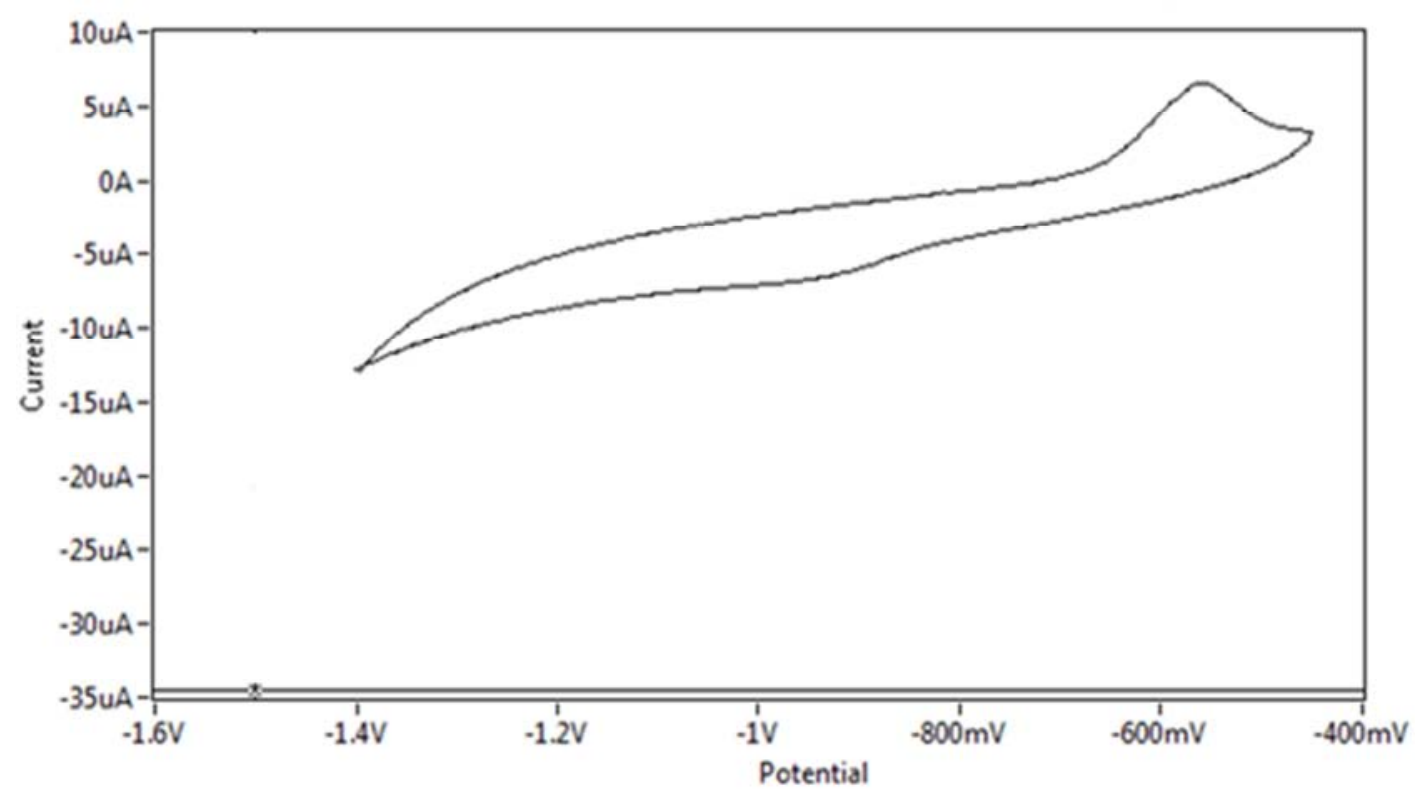

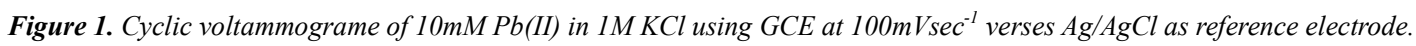

\subsection{Effect of AA on the Redox Current Peaks Pb(II)}

Figure 2 shows the voltammograme of $\mathrm{Pb}$ (II) ions in $1 \mathrm{M}$ $\mathrm{KCl}$ with ascorbic acid, which causes an enhancement of both redox current peaks of $\mathrm{Pb}(\mathrm{II})$ comaring without $\mathrm{AA}$ solution as in Figure 1. It seems that AA enhancement the oxidation current peak of $\mathrm{Pb}(\mathrm{II})$ about seven times and two times of the reduction peak.

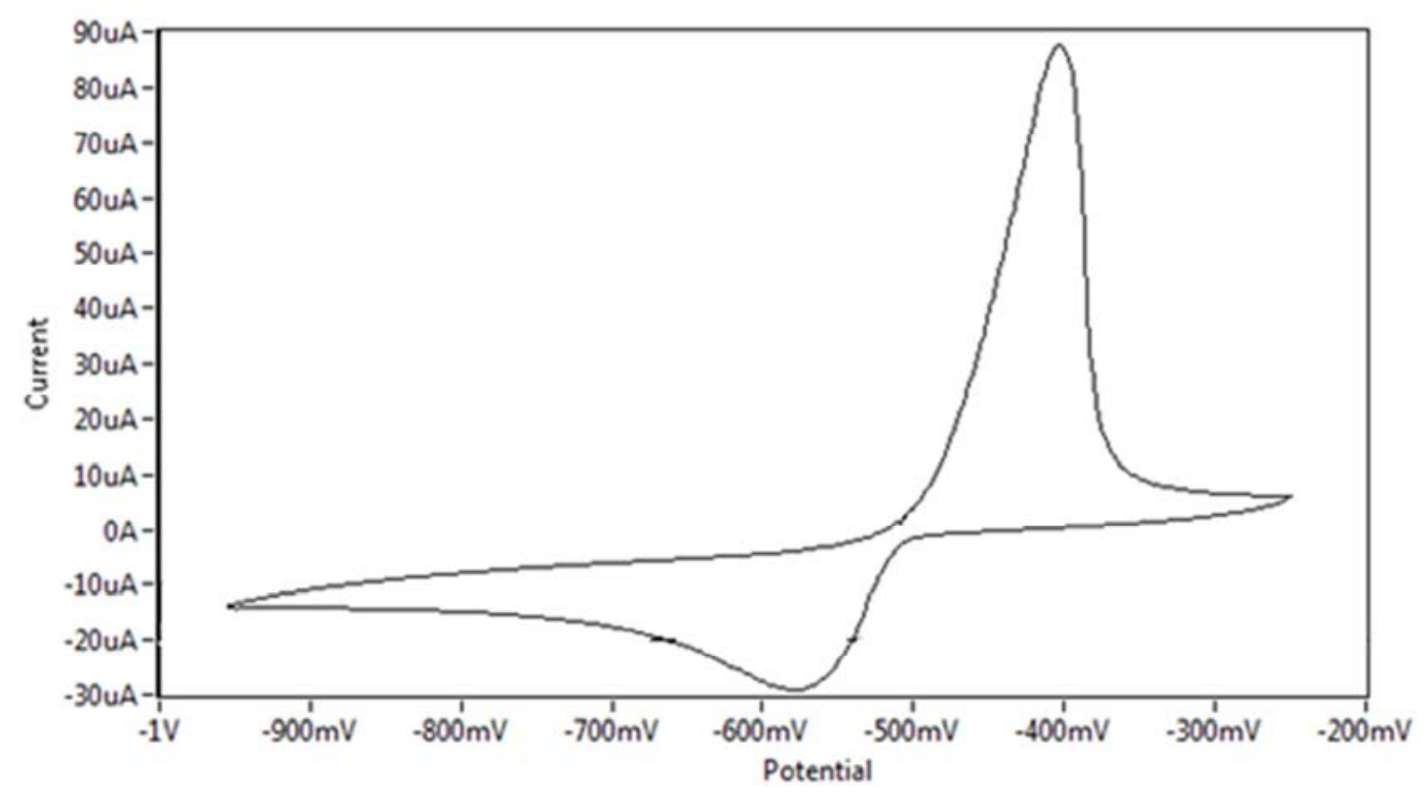

Figure 2. Cyclic voltammograme of $10 \mathrm{mM} P \mathrm{~Pb}(\mathrm{II})$ in present with $\mathrm{AA}$ in $1 \mathrm{M} \mathrm{KCl}$ using $\mathrm{GCE}$ at $100 \mathrm{mVsec}{ }^{-1}$ verses $\mathrm{Ag} / \mathrm{AgCl}$ as reference electrode. 
Figure 4. cyclic voltammograme of $10 \mathrm{mM} \mathrm{Pb}(\mathrm{II})$ in human blood sample using $\mathrm{GCE}$ at $100 \mathrm{mVsec}^{-1}$ verses $\mathrm{Ag} / \mathrm{AgCl}$ as reference electrode.

\subsection{Effect of Blood Medium on the Redox Current Peaks $\mathrm{Pb}(\mathrm{II})$}

It was found that blood medium using as electrolyte in the cell of the cyclic voltammetric technique to finding the electrochemical properties through the oxidation reduction peaks of the pollutants in the blood components. Figure 3 shows the oxidation current peak of $\mathrm{Pb}$ (II) in blood medium and disappearing the reduction current peak because of the properties of lead ions which work as an oxidative reagent in blood medium.

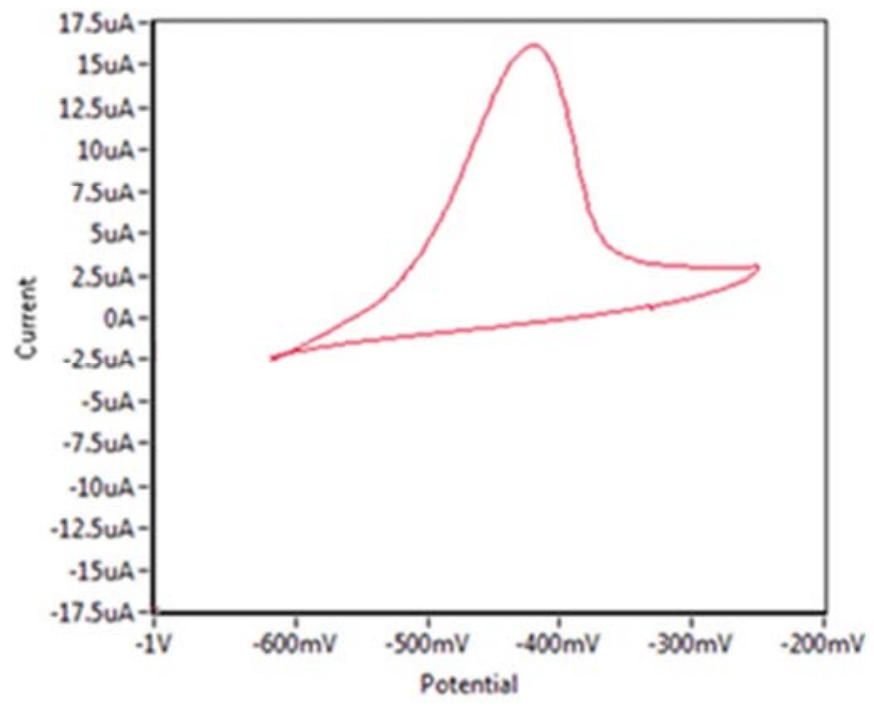

Figure 3. Cyclic voltammograme of $10 \mathrm{mM} P \mathrm{~Pb}(\mathrm{II})$ in human blood sample using GCE at $100 \mathrm{mVsec}{ }^{-1}$ verses Ag/AgCl as reference electrode.

\subsection{Effect of AA on the Redox Current Peaks of Pb(II) in Blood Medium}

It is well known in the analytical of electrochemistry espacially in cyclic voltammetric technique that AA has oxidation current peak [21] and this peak was affected on the behavior of oxidation and reduction current peaks in aqueous solutions, but the electrochemical properties have different in the vicinity of blood where it works as an anti-oxidant impact on the redox current peaks. Figure 4 and 5 show the big oxidation current peak of AA at $0.75 \mathrm{mV}$ has highly effected on the oxidation and reduction current peaks of $\mathrm{Pb}$ (II) in blood medium at $-0.4 \mathrm{mV}$ and $-0.7 \mathrm{mV}$ recepectively.

It was observed that the oxidation current of $\mathrm{Pb}^{2+}$ Gradually increases linearly with increasing of the concentration of AA by $\mathrm{Y}=0.0533 \mathrm{X}$ with correlation coefficient of $\mathrm{R}^{2}=0.919$ as shown in Figure 6. A slope of 0.5 was obtained, which is quite comparable with the theoretical slope of 0.5 for a diffusion controlled process [22].

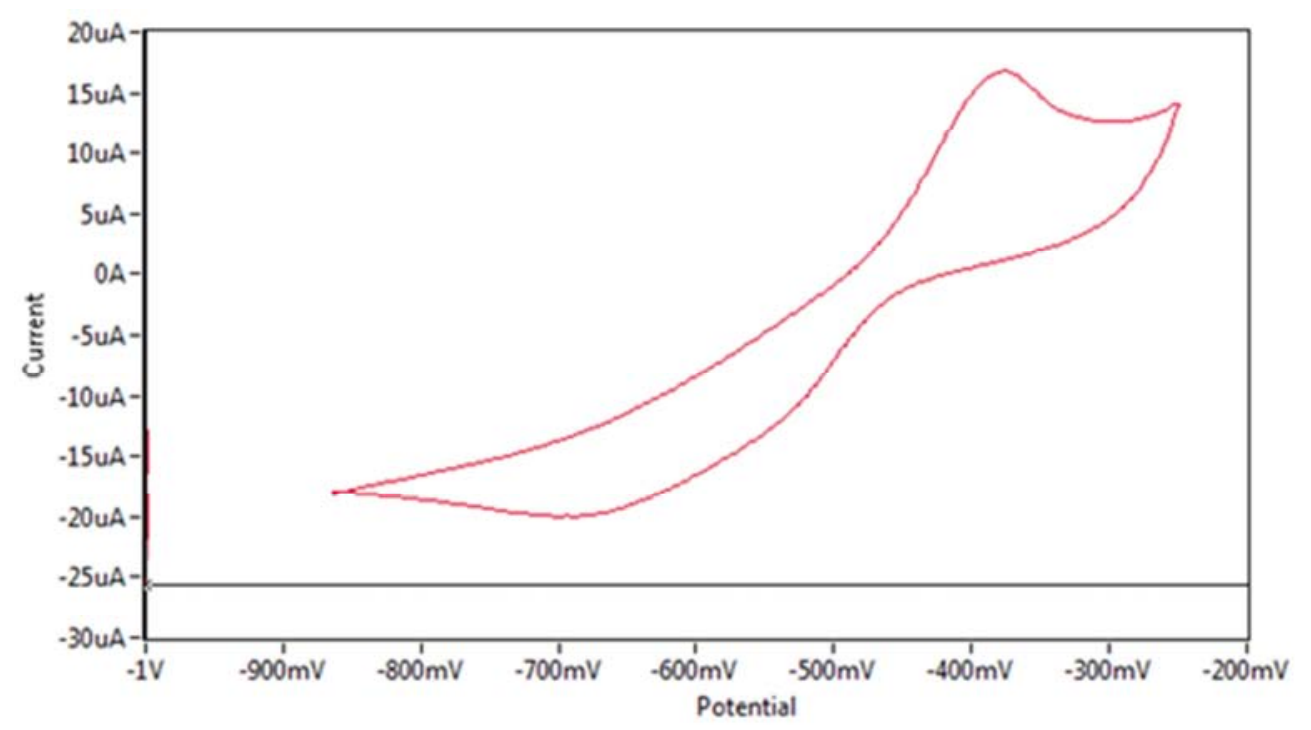

Figure 4. Cyclic voltammograme of $10 \mathrm{mM} P$ P(II) in present with AA in human blood sample using GCE at $100 \mathrm{mVsec} \mathrm{Serses}^{-1} \mathrm{Ag} / \mathrm{AgCl}$ as reference electrode. 


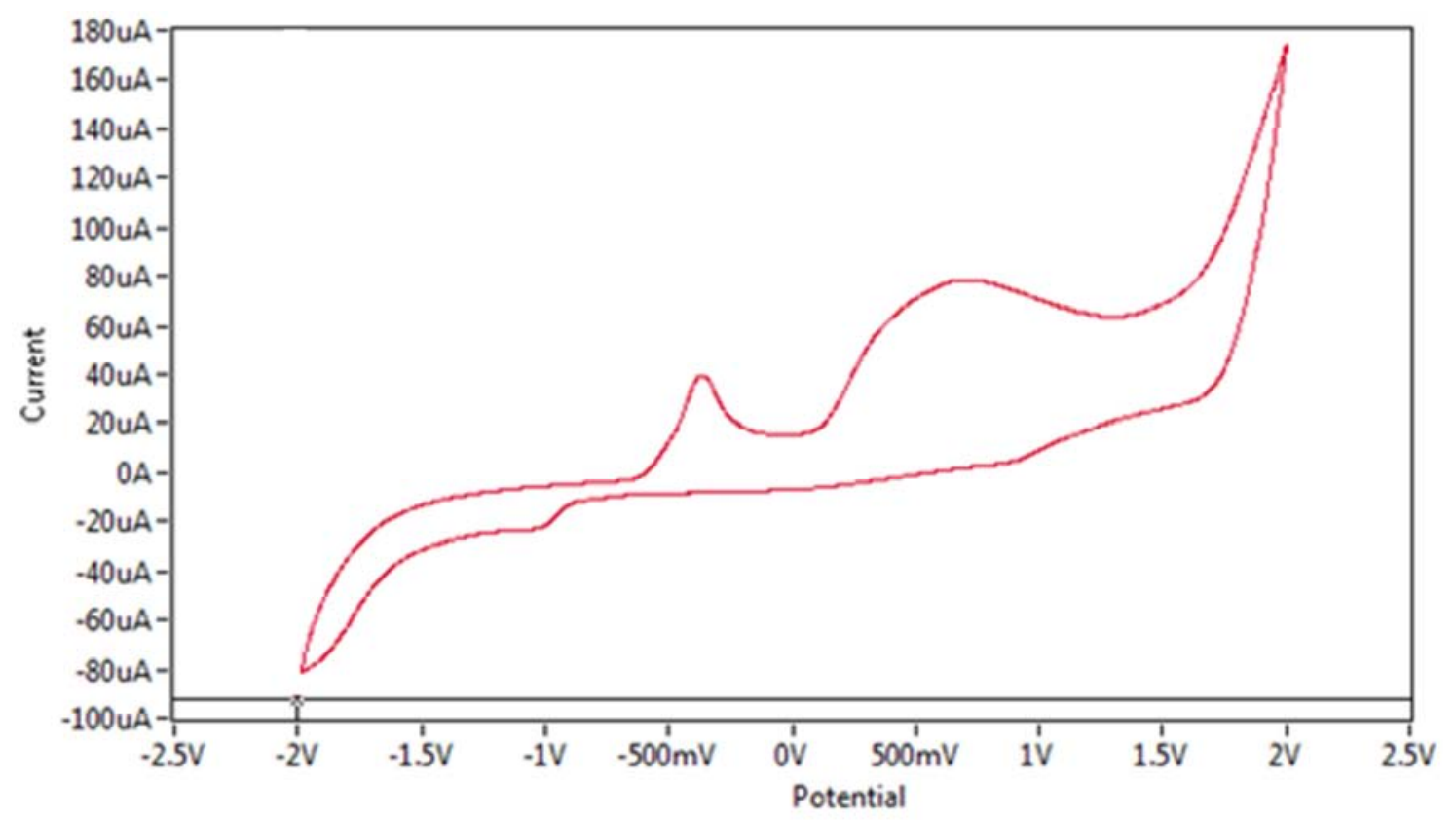

Figure 5. Cyclic voltammograme of $10 \mathrm{mM} P$ P(II) in present with AA in human blood sample using GCE at $100 \mathrm{mVsec} \mathrm{Serses}^{-1} \mathrm{Ag} / \mathrm{AgCl}$ as reference electrode.

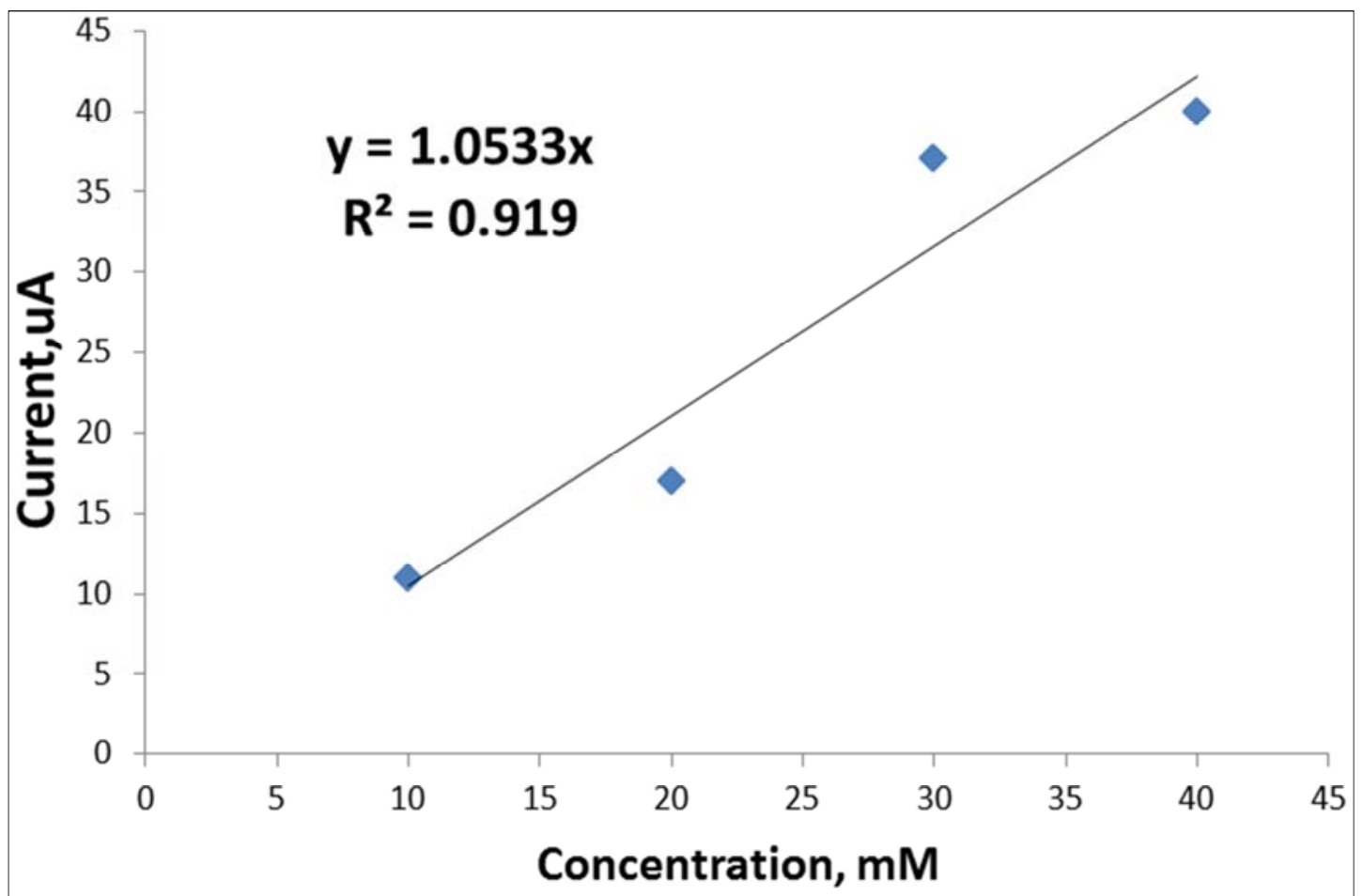

Figure 6. Plot of anodic current peak (IPa) against the different concentration of AA in blood medium with lead ions using GCE at $100 \mathrm{mVsec} \mathrm{C}^{-1}$ verses $\mathrm{Ag} / \mathrm{AgCl}$ as reference electrode.

\subsection{Effect of FA on the Redox Current Peaks of Pb(II) in Blood Medium}

Through previous studies of FA is an anti-oxidizing agent in aqueous solutions [23], when electrochemical studies have been used in the medical field especially in blood medium to their importance of the pollutants such as lead ions. Figure 7 shows the affect of FA on the oxidation and reduction current peaks of $\mathrm{Pb}(\mathrm{II})$ in blood medium at $-0.45 \mathrm{mV}$ and $-0.9 \mathrm{mV}$ respectively. It was determined from Figure 7 and comparative with Figure 3 that FA enhanced the reduction current peak of $\mathrm{Pb}$ (II) ions about five times and the FA can be conceder as an antioxidant reagent in blood medium, while reducing of oxidation current peak of $\mathrm{Pb}$ (II).

The calibration plot as in Figure 8 was performed at the GCE in $10 \mathrm{mM} \mathrm{Pb}^{2+}$ solutions with a good linearity of anodic current versus different concentration of FA described by $\mathrm{Y}=$ $0.2764 X, R^{2}=0.9411$. 


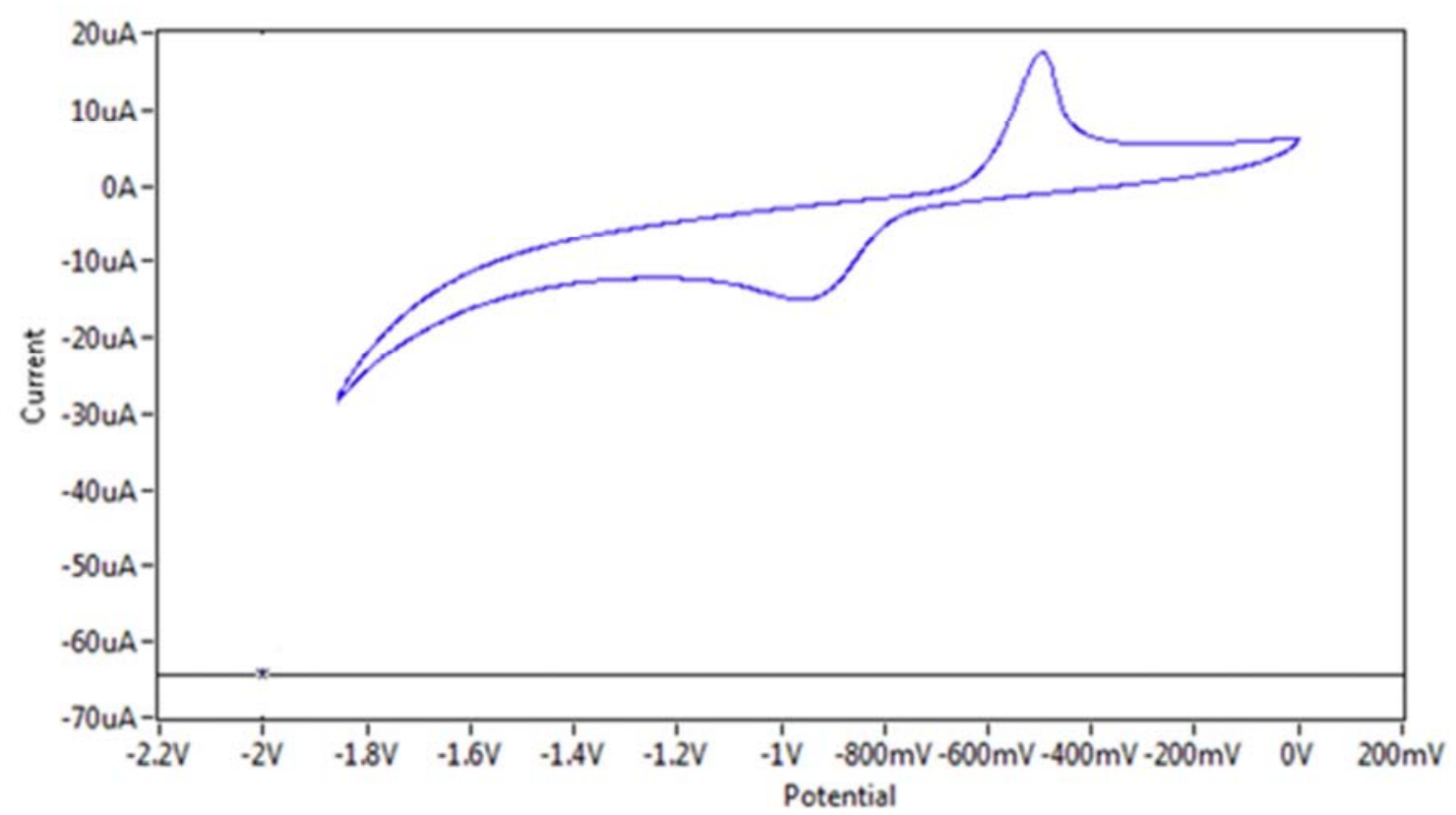

Figure 7. Cyclic voltammograme of $10 \mathrm{mM} P \mathrm{~Pb}(\mathrm{II})$ in present with FA in human blood sample using GCE at 100mVsec ${ }^{-1}$ verses Ag/AgCl as reference electrode.

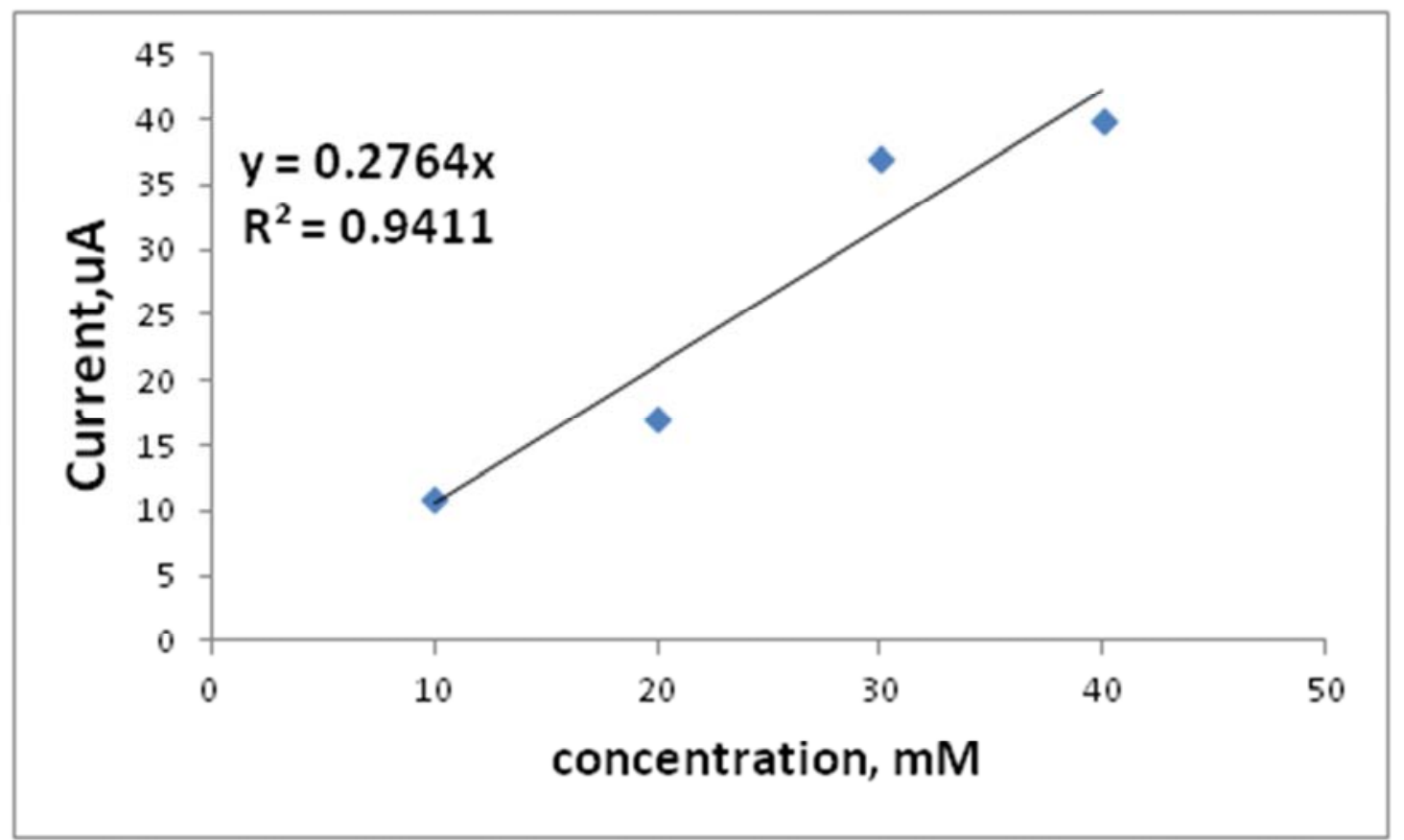

Figure 8. Plot of anodic current peak $\left(I_{P a}\right)$ against the different concentration of FA in blood medium with lead ions using GCE at $100 \mathrm{mVsec}{ }^{-1}$ verses $\mathrm{Ag} / \mathrm{AgCl}$ as reference electrode.

\subsection{Analysis of Pb(II) in Blood Medium}

The determination of AA concentration in blood samples with $\mathrm{Pb}^{2+}$ using GCE. Recoveries experiment were evaluated using direct calibration of $99.6 \pm 2.09 \%$ was obtained after the addition of $0.02 \mathrm{mM}$ AA in to blood sample with $\mathrm{Pb}^{2+}$ as in table 1 while recovery of $99.03 \pm 2.1 \%$ was obtained after the addition of $0.03 \mathrm{mM}$ AA into blood sample with $\mathrm{Pb}^{2+}$ as in table 2 .
Table 1. Recovery rate of $0.02 \mathrm{mM}$ of $A$ A added in to the blood sample with $\mathrm{Pb}(I I)$.

\begin{tabular}{lllll}
\hline $\begin{array}{l}\text { No. of } \\
\text { sample }\end{array}$ & $\begin{array}{l}\text { Concentration } \\
\text { of AA }(\mathbf{m M})\end{array}$ & $\begin{array}{l}\text { Recovery } \\
\text { Rate\% }\end{array}$ & $\begin{array}{l}\text { Mean } \\
\text { Recovery\% }\end{array}$ & $\begin{array}{l}\text { Relative } \\
\text { Standard } \\
\text { Deviation\% }\end{array}$ \\
\hline 1 & 0.0205 & 102.5 & 99.6 & 2.09 \\
2 & 0.0199 & 99.6 & & \\
3 & 0.0198 & 99.0 & & \\
\hline
\end{tabular}


Table 2. Recovery rate of $0.03 \mathrm{mM}$ of AA added in to the blood sample with $\mathrm{Pb}(I I)$

\begin{tabular}{lllll}
\hline $\begin{array}{l}\text { No. of } \\
\text { sample }\end{array}$ & $\begin{array}{l}\text { Concentration } \\
\text { of AA }(\mathbf{m M})\end{array}$ & $\begin{array}{l}\text { Recovery } \\
\text { Rate\% }\end{array}$ & $\begin{array}{l}\text { Mean } \\
\text { Recovery\% }\end{array}$ & $\begin{array}{l}\text { Relative } \\
\text { Standard } \\
\text { Deviation\% }\end{array}$ \\
\hline 1 & 0.0305 & 101.6 & 99.03 & 2.1 \\
2 & 0.0290 & 96.6 & & \\
3 & 0.0295 & 98.3 & & \\
4 & 0.0299 & 99.6 & & \\
\hline
\end{tabular}

\section{Conclusion}

Cyclic voltammetric technique was succeeded for using in the effect of lead ions as an oxidizing agent on blood components. It was found that oxidation current peak of lead ions in blood medium was enhanced about seven times and the reduction current peak was disappeared. AA was added to the lead ions in blood medium to acting as an antioxdative reagent by enhancing the reduction current peak, this mean that the patients whom are exposure to pollution of lead ions can be taking AA solution to reducing the oxidative effect. Also, in the same phenomena when using FA solution, it was found that FA acts as an antioxidative reagent in blood medium with lead ions in high activity by reducing the anodic current peaks and enhancing the cathodic current peak of $\mathrm{Pb}(\mathrm{II})$. So we concluded that using mixture of AA and FA solution for the patients whom working in the field of the high exposure with pollution with $\mathrm{Pb}$ ions.

\section{References}

[1] Heo Y1, Parsons PJ, Lawrence DA, Lead differentially modifies cytokine production in vitro and in vivo, Toxicol Appl Pharmacol. 1996 May; 138 (1): 149-57.

[2] Zhao Y1, Xu L, Li S, Chen Q, Yang D, Chen L, Wang H, Onedrop-of-blood" electroanalysis of lead levels in blood using a foam-like mesoporous polymer of melamine-formaldehyde and disposable screen-printed electrodes., Analyst. 2015 Mar 21; 140 (6): 1832-6.

[3] Shinde Brijalal Ramdas, Ascorbic Effect on the endosulphan induced alterations in Blood Glucose level of the Freshwater Fish, Central European Journal of Experimental Biology, 2013, 2 (3): 1-3.

[4] tiziana gugliotta, grazia de luca, pietro romano, caterina rigano, adriana scuteri and leonardo romano, effects of lead chloride on human erythrocyte membranes and on kinetic anion sulphate and glutathione concentrations, cellular \& molecular biology letters Volume 17 (2012) pp 586-597.

[5] M. G. Tan, G. L. Zhang, X. L. Li, Y. X. Zhang, W. S. Yue, J. M. Chen, Y. S. Wang, A. G. Li, Y. Li, Y. M. Zhang, and Z. C. Shan, Comprehensive Study of Lead Pollution in Shanghai by Multiple Techniques, Anal. Chem. 2006, 78, 8044-8050.

[6] Md. Kawser Ahmed, Elora Parvin, Md Monirul Islam, Mosammat Salma Akter, Md. Shahneawz Khan, Md Habibullah Al Mamun, Lead- and cadmium-induced histopathological changes in gill, kidney and liver tissue of freshwater climbing perch Anabas testudineus (Bloch, 1792), Chemistry and Ecology 2014; 30 (6).
[7] Muhammed Mizher Radhi, Wee Tee Tan, Mohamad Zaki B. Ab Rahman and Anuar Bin Kassim, Voltammetric Detection of Mn (II) in Blood Sample at C60 and MWCNT Modified Glassy Carbon Electrodes. American Journal of Applied Sciences 7 (3): 439-445, 2010.

[8] Muhammed M. Radhi, Dawood S. Dawood, Nawfal K. AlDamlooji and Tan W. Tee, Development of Electrochemical Sensors for the Detectionof Mercury by $\mathrm{CNT} / \mathrm{Li}+, \mathrm{C} 60 / \mathrm{Li}+$ and Activated Carbon Modified Glassy Carbon Electrode in Blood Medium Sensors \& Transducers Journal, Vol. 146, Issue 11, November 2012, pp. 191-202.

[9] Muhammed Mizher Radhi, Nawfal Khalid Al-Damlooji, Baquir Kareem Abed, Dawood Salman Dawood, and Tan Wee Tee, Electrochemical Sensors for Detecting Mn (II) in Blood Medium Sensors \& Transducers, Vol. 149, Issue 2, February 2013, pp. 89-93.

[10] Muhammed Mizher Radhi, Nawfal K. Al-Damlooj, Mahmood Radhi Jobayr, Dawood S. Dawood, Electrochemical Sensors of Cyclic Voltammetry to Detect Cd (II) in Blood Medium Sensors \& Transducers, Vol. 155, Issue 8, August 2013, pp. $150-154$.

[11] 11. Jiri Sochor, Jiri Dobes, Olga Krystofova, Branislav Ruttkay-Nedecky, Petr Babula, Miroslav Pohanka, Tunde Jurikova, Ondrej Zitka, Vojtech Adam, Borivoj Klejdus, Rene Kizek, Electrochemistry as a Tool for Studying Antioxidant Properties, Int. J. Electrochem. Sci., 8 (2013) 8464-8489.

[12] Parsons P. J., Analytical procedures for the determination of lead in blood and urine; approved guideline. Wayne, PA, National Committee for Clinical Laboratory Standards, 2001.

[13] Yin Wang, Jinping Jia, Electrochemical Determination of Lead (II) by Electrolyte Dropping Electrode Using 8Hydroxyquinoline in Flow Injection System, 9 th OAPS Working Paper Series Paper No. 2012-059.

[14] M. Ogunlesi, W. Okiei1, A. S. Akanmu and T. Popoola, K. Okafor, and O. Akore, Novel Method for the Determination of Haemoglobin Phenotypes by Cyclic Voltammetry using Glassy Carbon Electrode, Int. J. Electrochem. Sci., 4 (2009) 1593-1606.

[15] Feldman BJ1, D'Alessandro A, Osterloh JD, Hata BH, Electrochemical determination of low blood lead concentrations with a disposable carbon microarray electrode, Clin Chem. 1995 Apr; 41 (4): 557-63.

[16] David Hynek, Jan Prasek, Jiri Pikula, Vojtech Adam, Pavlina Hajkova, Ludmila Krejcova, Libuse Trnkova, Jiri Sochor, Miroslav Pohanka, Jaromir Hubalek, Miroslava Beklova, Radimir Vrba and Rene Kizek, Electrochemical Analysis of Lead Toxicosis in Vultures, Int. J. Electrochem. Sci., 6 (2011) $5980-6010$

[17] Guo Mai, Lu Xia, Weixing Wang, Electrochemical detection of blood lead based on the enhancement effect of copper, Russian Journal of Electrochemistry May 2013, Volume 49, Issue 5, pp 447-452.

[18] Yanfang Zhao, ab Lubin Xu, ab Shuying Li, a Qi Chen, a Daoshan Yang, a Lingxin Chenc and Hua Wang, "One-dropof-blood" electroanalysis of lead levels in blood using a foamlike mesoporous polymer of melamine-formaldehyde and disposable screen-printed electrodes, Analyst, 2015, 140, 1832-1836. 
[19] Zhihong Nie, a Christian A. Nijhuis, a Jinlong Gong, a Xin Chen, a Alexander Kumachev, b Andres W. Martinez, a, Max Narovlyanskya and George M. Whitesides, Electrochemical sensing in paper-based microfluidic devices, Lab Chip, 2010, $10,477-483$.

[20] Andrea Cserey, Determination of Lead (II) with the Rotating Sample System, Electroanalysis Volume 16, Issue 16, pages 1299-1304, August 2004.

[21] Koh Sing Ngai, Wee Tee Tan, Zulkarnain Zainal, Ruzniza Mohd Zawawi, Mohammed Zidan, Voltammetry Detection of Ascorbic Acid at Glassy Carbon Electrode Modified by Single-Walled Carbon Nanotube/Zinc Oxide, Int. J.
Electrochem. Sci., 8 (2013) 10557-10567.

[22] Muhammed M. Radhi, Wee T. Tan, Mohamad Z. B Ab Rahman and Anuar Bin Kassim, Electrochemical Characterization of the Redox Couple of $[\mathrm{Fe}(\mathrm{CN}) 6]^{3+} /[\mathrm{Fe}(\mathrm{CN}) 6]^{4+}$ Mediated by a Grafted Polymer Modified Glassy Carbon Electrode, journal of chemical engineering of Japan, vol. 43, no. 11, 2010.

[23] M. R. Majidi, H. Dastangoo, M. Hasannejad and J. Malakouti, Voltammetric Determination of Folic Acid with a Overoxidized Polypyrrole Film Modified Sol-Gel Carbon Ceramic Electrode, International Journal of Polymer Analysis and Characterization, Volume 16, Issue 7, 2011. 